\title{
Pedagogical Significance of Morphological Awareness in Korean and English
}

\author{
Young Ok Jong ${ }^{1} \&$ Chae Kwan Jung ${ }^{2}$ \\ ${ }^{1}$ Global Edu Reserach Institute, Global Edu Foundation, Incheon, South Korea \\ ${ }^{2}$ Division of Curriculum, Korea Institute for Curriculum and Evaluation, Seoul, South Korea \\ Correspondence: Chae Kwan Jung, Division of Curriculum, Korea Institute for Curriculum and Evaluation, \\ 21-15 (Jeongdong), Jeongdong-gil, Jung-gu, Seoul, 100-784, South Korea. Tel: 82-2-3704-5992. E-mail: \\ ckjung@kice.re.kr
}

Received: May 10, 2015 Accepted: June 24, 2015 Online Published: July 25, 2015

doi:10.5539/elt.v8n8p79 URL: http://dx.doi.org/10.5539/elt.v8n8p79

\begin{abstract}
This study investigated whether Korean children understand the internal structure of compound words in Korean and English and whether there is a relationship between their performance in tasks that measure their understanding of the morphological structure of compounds in Korean and English. This study also examined the effects of gender, grade, and verbal ability on the performance of the Korean and English tasks. 106 primary school children completed a Korean and English compound task, which consisted of 32 compound test items in Korean and in English respectively. Each compound task included 16 comprehension test items and 16 production test items. Half of them were real words and the other half were pseudo words. The structures of the compounds were noun-noun or noun-verb. Korean task scores made a significant contribution to predicting English test scores after controlling for gender, grade, and verbal ability. It is concluded that L1 task performance can be a significant factor in L2 task performance, supporting evidence that L1 morphological awareness is transferable to L2 morphological processes. From a pedagogical perspective, research findings will be useful for teachers when designing compound tasks to develop Korean children's morphological awareness for language and literacy development in English.
\end{abstract}

Keywords: Korean, English literacy development, morphological awareness, compound words, language transfer

\section{Introduction}

Korean parents pay great attention to their child's literacy development with high expectations of academic achievement, because they believe that reading and writing readiness skills are crucial and should be acquired before entering primary school (Lee, 2002; Park, 2008). For example, 4-year-old children are taught to read syllable blocks and 5-year-old children are taught to read combining consonant-vowel syllables with final consonants at home by parents or at kindergartens by tutors (Cho et al., 2008; Lee et al., 2000). In this way, preschoolers are expected to have basic Korean literacy skills before they start school at the age of 6 or 7 . Therefore, Korean children can become literate at a very early age.

As is well revealed in the term, 'English fever', English has been the most important foreign language to learn in conjunction with the government's globalization policy since the mid-1990s (Park, 2009; Shin, 2007). With the tremendous degree of attention to English, there has been a constant demand to teach English through English resulting from the frustrating results in Korean students' low levels of English proficiency even after ten years' English learning experience (MOE, 2007). Recently, however, there has been an increasing interest in the development of reading and writing skills (Jong, 2009, 2013), because written English has become a predominant medium on the internet (Crystal, 2006). Despite the increasing interest in the development of literacy skills, the role of English morphological awareness has not been paid sufficient attention as an effective way to foster English reading and writing skills. In addition, little attention has been given to the development of Korean primary school children's morphological awareness, which may become a powerful contributor to the development of English morphological awareness under the current national curriculum.

A growing body of research studies has acknowledged the contribution of morphological knowledge to language 
development. More specifically, recent studies have extensively examined morphological awareness in bilingual children, because young L2 learners' knowledge of word structure and word formation rules is related to their early literacy development (Carlisle, 2005; Koda, 2005; McBride-Chang et al., 2005; Nicoladis, 2003a, 2003b; Nunes \& Bryant, 2006, 2009; Ramirez et al., 2010; Wang et al., 2005, 2006a, 2006b, 2009). This is of interest for theories about L1 and L2 acquisition because previous L1 morphological processing experience can become a reliable and valid predictor of the development of L2 morphological awareness (Koda, 2005; Koda \& Zehler, 2008). It would be reasonable to expect Korean children to use their L1 morphological knowledge in processing English L2 morphology.

Until now, few empirical studies have been conducted to explore Korean children's awareness of the internal structure of compound words in Korean and English. From a pedagogical perspective, it is worthwhile to investigate whether Korean children understand the structure of compound words in Korean and English and whether there is a relationship between their performance in tasks to measure their understanding of the morphological structure of compounds in the two. If this relationship exists, it can be expected that Korean children benefit from understanding the patterns of word formation in their own language when learning English.

\section{Research Background}

\subsection{Morphological Awareness and Literacy Development}

Two metalinguistic skills, phonological awareness and morphological awareness have been considered to facilitate reading and writing skills across languages, but much more attention has been given to the contribution of phonological awareness to literacy development (Gillion, 2004). When learning a written language, awareness of the constituent sounds of words is a reliable predictor of reading comprehension and thus, it is important to develop children's phonological awareness, which refers to "the ability to reflect on and manipulate the structure of an utterance (e.g., into words, syllables, or sounds) as distinct from its meaning" (Stackhouse, 1997, p. 157). If children can successfully divide words by phonemes which are the smallest unit of sound in a spoken word and then synthesize these speech sounds to make words, it would be helpful to read and write words correctly at a young age such as three phonemes $/ \mathrm{k} /, / \mathfrak{x} /$ and $/ \mathrm{t} /$ in a word 'cat'. There are three types of words which may make children difficult to connect the sound, spelling and meaning of words when the words are told. The three types are homophones with the same sound but a different spelling and meaning (e.g., there, their, they're), homographs with the same spelling but a different sound and meaning (e.g., tear: to split or to drop water from the eye), and homonyms with the same sound and spelling but a different meaning (ball: a round object or a dance). As English L2 learners, Korean children may feel more confused when they are told these three types of words.

Along with the importance of reflecting on the sound components of spoken words in literacy development, a growing body of research has acknowledged the role of morphological awareness, which refers to "the ability to reflect on and manipulate morphemes and employ word formation rules in a language" (Kuo \& Anderson, 2006, p. 161). Morphemes, the smallest meaningful units of a word, are either free or bound depending on whether the units can stand alone. For instance, 'toys' is divided into a free morpheme 'toy' and a bound morpheme '-s'. Words are either monomorphemic or multimorphemic depending on whether they are broken down into smaller morphemes. While 'pneumoconiosis' cannot be divided into smaller parts, 'unsystematically' is divided into five meaningful components, 'un', 'system', 'atic', 'al' and 'ly'. Therefore, it seems to be much easier for Korean children to understand the internal structure of English words with knowledge of morphemes.

Although the role of phonological awareness and morphological awareness can differ from language to language, there are sound educational reasons to develop children's morphological awareness. Recent studies have acknowledged that morphological awareness is a strong predictor of the development of literacy skills (Nagy et al., 2003, 2006; Carlisle, 1995, 2005; Deacon \& Kirby, 2004; Fowler \& Liberman, 1995; Ku \& Anderson, 2003, Kuo \& Anderson, 2006; McBride-Chang et al., 2005). Morphological awareness refers to a learners' grasp of morphological structure and the learner's capability of using this knowledge during morphological processing in visual word recognition (Koda, 2000). Therefore, poor word recognition may restrict experience with morphologically complex words and in turn, this limits the development of morphological awareness. In a study of fourth and seventh grade Spanish-speaking English-learning children, morphological awareness played a significant role in word reading in Spanish and English (Ramirez et al., 2010). In a study of second and fourth grade Korean-English bilingual children, morphological awareness was a significant predictor of word reading and reading comprehension in Korean and English (Wang et al., 2009). Although different words have different learning burdens for learners with different language background (Nation, 2001), a number of studies have discussed the role of morphological awareness in relation to the development of literacy skills. 


\subsection{Morphological Awareness and Language Transfer}

There has been considerable attention paid to the extent of language transfer, which refers to "the influence resulting from the similarities and differences between the target language and any other language that has been previously (and perhaps imperfectly) acquired" (Odlin, 1989, p. 27). With a question of whether children's L1 morphological awareness is a good predictor of their L2 learning, recent studies have examined morphological awareness in bilingual children, such as French-English (Nicoladis, 2003a, 2003b), Chinese-English (Wang et al., 2005, 2006a, 2006b), Korean-English (Wang et al., 2009), Spanish-English (Ramirez et al., 2010). It is an important issue both theoretically and practically to explore whether morphological awareness can be applied cross-linguistically (Nunes \& Bryant, 2009). Considering the close connections between Spanish and English, Spanish-speaking children benefit from the same origin of words in the two languages (Carlo et al., 2004). For example, there are a large number of cognate pairs in English and Spanish (e.g., container-contener, journeyjournada). Therefore, the use of cognates could be predictive of reading English words. Concerning the distance between L1 and L2 orthographic systems, however, the role of morphological awareness may differ among the learners who have different language backgrounds, because L2 morphological awareness is strongly affected by different L1 experiences in word reading. However, it has been widely recognized that L1 morphological awareness is a reliable predictor of L2 morphological processes (Koda, 1996, 2005), even with different degree of transfer of morphological knowledge across languages. More specifically, recent studies on cross-language transfer of morphological knowledge have paid attention to comprehension and production of compound words.

\subsection{Word Formation and Compound Words}

As addressed, L2 children can develop a sense to infer the meaning of unfamiliar words if they understand how the words are formed. It is thus essential to develop Korean children's awareness of the rules of word formation in Korean and English.

Korean has three word formation rules: borrowing, derivation and compounding (Lee, 2003; Lee \& Ramsey, 2000; Song, 2005). Korean has long been in contact with other languages, resulting in a large proportion of borrowed words in written Korean. Among these languages, Chinese graphs were used for transcription prior to the invention of the Korean alphabet, Hangul. Therefore, current Korean vocabulary consists of native Korean words originating from Middle and Old Korean and Sino-Korean words from Chinese. For instance, the native Korean 나라 (country) is also written in the Sino-Korean (country). Korean has a very productive and complex inflectional morphology. Most derivations are generated by a means of suffixes rather than prefixes. For example, the morphological suffix 이 can be added to the adjective 넓 (wide) to form the noun 벏 이 (width) or to a verb like 먹 (eat) to form the noun 먹 이 (food). The most common and productive word formation process in Korean is compounding, which is a process of combining two or more words to create a new word. Compound words are written without a space or a hyphen. For example, 이글비 (drizzle) is a combination of the native Korean 이슬 (dew) and the native Korean 비 (rain) and 학년 (grade) is a combination of the Sino-Korean 학 (study) and the Sino-Korean 년 (year).

English has three basic word formation rules: inflection, derivation and compounding (Bauer, 1983; Plag, 2003). Inflection modifies word forms using prefixes and suffixes and changes the grammatical functions of the words. The past tense verb 'jumped' is an inflectional form of 'jump' made by adding the morphological suffix '-ed'. Derivation changes the meaning and the grammatical category of words using prefixes and suffixes. The adjective 'unkind' is a derivational form of 'kind' made by attaching the prefix '-un'. Compounding is a common word formation process of combining two or more words to create a new word. Compound words may be written with or without a space or with a hyphen (e.g., tomboy, chicken run, space-ship).

As mentioned, if L2 learners are sensitive to the morphological structure of words, this morphological awareness facilitates their literacy skills (Carlisle, 2005). The compound word, 'unforgettable' is broken down into three morphemes and each morpheme has its own grammatical function and meaning. The prefix 'un' changes the meaning of the word to its very opposite, the verb 'forget' is the basic part of the compound and the suffix 'able' changes the grammatical category of the word from a verb to an adjective. If L2 learners recognize the internal structure of such compound words and know the grammatical and functional role of their components, they can succeed to figure out meaning.

Compounding is a common and universal word formation process as well as a productive word formation process. In Korean, the most common compounds are noun compounds, followed by verb compounds. For example, 반친구 (classmate) is a combination of the noun 반 (class) and the noun 친구 (friend). 소풍가다 (go on a picnic) is a combination of the noun 소풍 (picnic) and the verb 가다 (go). It is thus crucial for Korean children to recognize the internal structure of compound words to expand their Korean vocabulary. According to 
Bauer (1983), English compounds are classified depending on their function in the sentences (e.g., noun, verb, adjective) or the word classes that consist of the compounds (e.g., noun-noun, noun-verb) as presented below (Table 1).

Table 1. Types of English compounds words (Carstairs-McCarthy, 2002, pp. 44-56)

\begin{tabular}{lll}
\hline Classes & Structure & Example \\
\hline \multirow{4}{*}{ Compound nouns } & Noun-noun & Hair-pin \\
& Verb-noun & Play-time \\
& Adjective-noun & Black-board \\
& Preposition-noun & Out-post \\
\hline \multirow{3}{*}{ Compound verbs } & Verb-verb & Stir-fry \\
& Noun-verb & Hand-wash \\
& Adjective-verb & Dry-clean \\
& Preposition-verb & Over-cook \\
\hline \multirow{3}{*}{ Compound adjectives } & Noun-adjective & Oil-rich \\
& Adjective-adjective & Squeaky-clean \\
& Preposition-adjective & Over-active \\
\hline
\end{tabular}

As Clark (2001) noted, productivity of compound word formation is dependent on the nature of language. For instance, 'handbrush' and 'brushbag' can be coined based on the existing compound words, 'handbag' and 'toothbrush'. This process may enable both English-speaking children and English-learning children to learn new English words in an effective way. To a large extent, Korean children can benefit from the knowledge of word formation rules in English in terms of literacy development.

\subsection{Compounds and Language Transfer}

In contrast to extensive research on inflectional derivational word formation rules, a relatively small number of studies have investigated children's comprehension and production of compounds. In a study of preschoolers and second graders in Hong Kong, McBride-Chang et al. (2003) asked them to produce novel compound words with questions such as There is a home appliance that is used to wash clothes. It is called a washing machine [literally, wash clothes machine]. If a home appliance could be used to wash shoes, what would you call that? This study reported that morphological awareness was uniquely predictive in reading English words because compounding is the most common word formation process in Chinese. In a comparative study on the object-verb-er compounds (e.g., can-open-er), Murphy and Nicoladis (2006) found that British preschoolers produced more ungrammatical compounds than Canadian preschoolers. After working with practice items such as Here is a machine that is watering a hat. We could call that a hat waterer, the children were asked to name a machine in ten different pictures. Although the object-verb-er form is grammatical in English and the verb-object form is grammatical in French, British preschool children produced more verb-object compounds and fewer object-verb-er compounds than Canadian children. While British children become familiar with the object-verb-er at the age of four years, the French children seem to produce the complex compound words according to their experiences (e.g., roller skate, fire fighter). In a comparative study of fifth grade Chinese-speaking English L2 children, Zhang et al. (2010) investigated four types of compounds (i.e., noun-noun, verb-noun, noun-verb, verb-particle) to examine implicit knowledge about the internal structure of compounds in Chinese and English. In the comprehension task, the children were asked to complete Chinese and English compound word structure tasks such as 'Cook over: (a) fish car (b) egg road (c) ask by' in order to measure their awareness of the verb-particle structure of compounds in English. This comprehension task was a study to identify cross-language transfer of awareness of the structure of four types of compound words in Chinese and English. In a cross-national study of second graders in Beijing, Hong Kong, Korea and America (McBride-Chang et al., 2005), Korean children were asked to create compound words such as When $a$ refrigerator keeps Kimchi in it, then we call it Kimchi refrigerator. If a refrigerator keeps a flower in it, what would we call it? This task was to assess their abilities to manipulate familiar morphemes to construct novel compounds. In an empirical study of 8- to 11-year-old English-speaking, Nunes et al. (1997b) tested the 
knowledge of the morphological inflection '-ed' and found that the children applied the same processes used in the spelling of regular real verbs to spelling regular pseudo-verbs (e.g., yell-yelled to crell-crelled). This provided direct evidence that children could recognize morphologically complex words and dealt with unfamiliar words as one of the most fundamental aspects of literacy skills. To date, Korean children's awareness of the internal structure of compounds remains largely unexplored and there is a need to examine Korean children's ability to comprehend and produce compounds in Korean and English.

\section{Rsearch Design}

In order to investigate whether Korean children understand the internal structure of compounds in Korean and English, whether there is a relationship between the performance of Korean and English compound tasks and more specifically whether there are the effects of gender, grade and verbal ability on task performance, the research questions were formulated to meet the specific inquiries as follows:

Q1: Is there a relation between Korean children's awareness of the internal structure of compound words in Korean and English?

Q2: How does gender affect compound test scores in Korean and English?

Q3: How does grade affect compound test scores in Korean and English?

Q4: How does verbal ability affect compound test scores in Korean and English?

\subsection{Participants}

1065 th and 6th grade Korean children participated in the study and none of them received special education during the period of data collection (see Table 2). Under the national curriculum, the children usually took the minimum of five Korean lessons and two English lessons per week. As the 5th graders had received two years of English instruction by the time they participated in the study, all the children were considered sufficiently adept to perform the compound tasks in Korean and English.

Table 2. Demographic information for the participants

\begin{tabular}{llllll}
\hline & Classes & Boys & Girls & M & SD \\
\hline Grade 5 & 2 & 27 & 29 & 10.28 & 0.39 \\
Grade 6 & 2 & 25 & 25 & 11.24 & 0.37 \\
\hline
\end{tabular}

\subsection{Measures and Procedures}

\subsubsection{Vocabulary Test}

Although none of the participants received special education during the period of data collection, a Korean vocabulary test in the form of a modified version of the Receptive/Expressive Vocabulary Test (REVT, Seoul Community Rehabilitation Center, 2009) was taken to measure their general verbal intelligence. The REVT, a norm-referenced measure of receptive and expressive vocabulary for children and adults in Korean, is normally administered on a one-on-one basis, but its administration procedure was adapted for use in the classroom. For the 20-minute paper and pencil vocabulary test, 50 out of 185 items of the REVT were prepared for presentation to a whole class. The vocabulary test started 10 items prior to the recommended starting point in order to minimize the likelihood of observing a floor or a ceiling effect. All the instructions were oral and presented to the whole class in Korean.

\subsubsection{Compound Task}

A set of Korean and English compound task was taken to measure participants' understanding the internal structure of compounds in Korean and English. The compound task was a newly-developed version, used by Zhang et al. (2010) to assess Chinese children's ability to comprehend four types of compounds in Chinese and English and by McBride-Chang et al. (2005) to measure Korean children's ability to produce novel compounds in a cross-national study. The tasks consisted of 16 comprehension test items and 16 production test items in Korean and English (see Table 3). Half of them were real words and the other half were pseudo words. Half of them were noun-noun compounds and the other half were noun-verb compounds. The test items were mainly selected from the Korean writing textbooks and English textbooks for primary school children. Three primary school teachers checked all the test items for the appropriateness for primary school children. 
Table 3. Korean and English compound task

\begin{tabular}{lllll}
\hline Language & Task & Words & Structure & No. items SD \\
\hline \multirow{4}{*}{ Korean } & \multirow{2}{*}{ Comprehension } & Real & N/N & 4 \\
& \multirow{4}{*}{ Production } & Pseudo & N/V & 4 \\
& & Real & N/N & 4 \\
& & Pseudo & N/V & 4 \\
\hline \multirow{4}{*}{ English } & \multirow{2}{*}{ Comprehension } & Real & N/N & 4 \\
& \multirow{2}{*}{ Production } & Pseudo & N/V & 4 \\
& & Real & N/N & 4 \\
& & Pseudo & N/V & 4 \\
\hline
\end{tabular}

After eight practice items, a 30-minute paper and pencil compound task was taken to measure participants' ability to comprehend and produce compounds in Korean and English. For one of the Korean production real word task, the participants were asked that If you make a man with snow, it is called a snowman. If you make a watch with gold, what would you call it? The expected answer was 금시계, a sample of a noun-noun structure. For one of the English comprehension pseudo word task, they were asked the following items, 'horsetalk: (a) milkdrink; (b) longsleep; (c) earlywalk'. The expected answer was (a), a sample of a noun-verb structure.

\section{Analysis and Results}

\subsection{Descriptive Statistics for Measures}

\subsubsection{Sample and Measures}

After all the raw scores were obtained by adding up the individual scores, each raw score was converted into a standard score that was statistically equivalent to a standard deviation score (see Table 4). The participants obtained relatively higher scores on the vocabulary test compared to an age-equivalent reference group. Therefore, the participants of this study could be considered representative of the population. The scores of 6th children were higher than those of 5 th grade in both tasks.

Table 4. Descriptive statistics for age and measures

\begin{tabular}{lllll}
\hline & \multicolumn{2}{l}{ Grade $5(\mathrm{n}=56)$} & \multicolumn{2}{l}{ Grade $6(\mathrm{n}=50)$} \\
\cline { 2 - 5 } & $\mathrm{M}$ & $\mathrm{SD}$ & $\mathrm{M}$ & $\mathrm{SD}$ \\
\hline Age (in years) & 10.28 & 0.39 & 11.24 & 0.37 \\
Vocabulary raw score & 121.66 & 3.93 & 121.68 & 4.50 \\
REVT standard score & 99.00 & 8.33 & 108.00 & 8.49 \\
Korean compound score & 26.27 & 4.55 & 27.92 & 3.68 \\
English compound score & 17.02 & 7.97 & 21.78 & 7.87 \\
\hline
\end{tabular}

\subsubsection{Reliability and Validity}

Each response in the vocabulary test and the compound task was dichotomously coded as ' 1 ' to indicate a correct answer or ' 0 ' to indicate an incorrect answer. To evaluate the value of the two measures, a first step was to determine reliability which refers to test consistency and a prerequisite for the validity of a test. Among a number of procedures for estimating reliability, the present study used the split-half coefficient for the vocabulary test and Cronbach's alpha coefficient for the compound task. The reliability of the vocabulary test was evaluated using the split-half coefficient to compare the results of one half with the results of the other in the test, because the items became gradually difficult. The test items were divided into odd and even numbered halves, the level of difficulty in the two halves was likely to be similar to each other. Using the Spearman-Brown formula, the split-half reliability value of the vocabulary test was .736 , showing a moderate reliability of the measure. The reliability of the compound task was measured using the Cronbach alpha coefficient because the number of items was too small to use the split-half method. The Cronbach alpha coefficient for the Korean task was .807 and for 
the English task was .919, showing the good reliability of the measure. In order to verify the construct validity of the Korean and English compound task, factor analyses were conducted utilizing principal component analysis with Varimax as an extraction method and Kaiser normalization as a rotation method. A principal component analysis was conducted on the eight Korean compound constructs using varimax rotation of the factor loading matrix. When the factorability of the eight constructs was examined, six of them correlated at least .3 with at least one other item, suggesting reasonable factorability. The Kaiser-Meyer-Olkin measure verified the sampling adequacy for the analysis was .66, which was above the recommended value of .6. The Bartlett's test of sphericity was significant $\left(\mathrm{x}^{2}(28)=188.239, p<.01\right)$. The diagonals of the anti-image correlation matrix were all over .5, supporting the inclusion of each construct in the factor analysis. Finally, the communalities were all above .5 , further confirming that each construct shared some common variance with other constructs. When factor analysis was conducted with the eight constructs, three factors were initially extracted with eigenvalues equal to or greater than 1.00. As a similar manner in Korean, a principal component analysis was conducted on the eight English compound constructs. When an initial analysis examined the factorability of the eight constructs, all the items correlated at least 3 with at least one other item, suggesting reasonable factorability. The Kaiser-Meyer-Olkin measure of sampling adequacy was .82, higher than the recommended value of .6. The Bartlett's test of sphericity was significant $\left(\mathrm{x}^{2}(28)=546.069, p<.01\right)$. The diagonals of the anti-image correlation matrix were all over .5, supporting the inclusion of each variable into the factor analysis. Finally, the communalities were all above .4 , further confirming that each variable shared some common variance with other variables (Field, 2009; Healey, 2005; Muijs, 2004).

\subsection{Factor Analysis}

\subsubsection{Factors in Korean Compound Task}

As shown in Table 5, the orthogonal rotation of the factors produced the factor structure. Factor 1 can be interpreted as a comprehension dimension in the measurement of children's understandings of Korean compounds because all the comprehension tasks load mostly on this factor. $\mathrm{KC}$ accounted for $31.21 \%$ of the variance. Factor 2 is a production dimension, particularly, in the measurement of children's understanding of Korean noun-noun compound words as over half of the production tasks load on this factor. KPNN accounted for $22.12 \%$ of the variance. Factor 3 shows another production dimension assessing children's understanding of Korean noun-verb compound words. KPNV accounted for $13.87 \%$ of the variance. There was one overlapping construct (i.e., KPPNN) between Factors 2 and 3 and it was tentatively interpreted as a component of Factor 3 in this study.

Table 5. Orthogonal factor loading matrix based on a principal component analysis with varimax rotation for the eight Korean compound constructs

\begin{tabular}{llll}
\hline Variable & Factor 1 & Factor 2 & Factor 3 \\
\hline KCRNN & $\mathbf{. 6 7 5}$ & .099 & -.052 \\
KCRNV & $\mathbf{. 6 6 4}$ & .160 & .060 \\
KCPNN & $\mathbf{. 8 3 1}$ & -.142 & .079 \\
KCPNV & $\mathbf{. 8 2 6}$ & .003 & .151 \\
KPRNN & .195 & -.085 & $\mathbf{. 8 8 3}$ \\
KPRNV & .065 & $\mathbf{. 7 6 1}$ & .365 \\
KPPNN & -.076 & $\mathbf{. 5 0 4}$ & $\mathbf{. 6 5 1}$ \\
KPPNV & .084 & $\mathbf{. 8 7 0}$ & -.182 \\
Eigenvalues & 2.50 & 1.77 & 1.11 \\
Variance (\%) & 31.21 & 22.12 & 13.87 \\
Cumulative variance (\%) & 31.21 & 53.34 & 67.21 \\
\hline
\end{tabular}

Note. Factor loading of over .40 appear in bold. Korean (K), Comprehension (C), Production (P), Real (R), Pseudo (P), Noun (N), Verb (V). 
The Korean compound task was designed to include variance in the mode of response (comprehension vs. production), in the type of stimulus (real vs. pseudo words), and in the structure of the compound (noun-noun vs. noun-verb). The factor analysis suggested that the first and third variances - mode of response and structure of the compound - can be seen as dimensions emerging from the factor analysis; the difference between noun-noun and noun-verb compounds is more important in the production tasks. The significance of type of stimulus is less clear as the NV and NN tasks show highest loadings in the two factors regardless of real or pseudo words. The factor analysis provides evidence for the construct validity of these tasks. The high reliability of the items within a single task suggests that they can be used as a single measure in the regression analyses.

\subsubsection{Factors in English Compound Task}

When factor analysis was conducted with all the eight English compound constructs, two factors were initially extracted with eigenvalues equal to or greater than 1.00. As can be seen in Table 6, the orthogonal rotation of the factors produced the factor structure.

Table 6. Orthogonal factor loading matrix based on a principal component analysis with varimax rotation for the eight English compound constructs

\begin{tabular}{lll}
\hline Variable & Factor 1 & Factor 2 \\
\hline ECRNN & .327 & $\mathbf{. 6 1 8}$ \\
ECRNV & .114 & $\mathbf{. 7 7 3}$ \\
ECPNN & .017 & $\mathbf{. 7 7 0}$ \\
ECPNV & .251 & $\mathbf{. 6 0 2}$ \\
EPRNN & $\mathbf{. 8 6 6}$ & .283 \\
EPRNV & $\mathbf{. 9 1 7}$ & .157 \\
EPPNN & $\mathbf{. 9 1 6}$ & .253 \\
EPPNV & $\mathbf{. 9 2 8}$ & .102 \\
Eigenvalues & 4.15 & 1.44 \\
Variance (\%) & 51.85 & 18.03 \\
Cumulative variance (\%) & 52.85 & 69.88 \\
\hline
\end{tabular}

Note. Factor loading of over .40 appear in bold. English (E), Comprehension (C), Production (P), Real (R), Pseudo (P), Noun (N), Verb (V).

Factor 1 can be interpreted as a production dimension in assessing children's understanding of English compounds because all the production tasks load on this factor. EP accounted for $51.85 \%$ of the variance. Factor 2 can be interpreted as a comprehension dimension in the measurement of children's understandings of English compounds because all the comprehension tasks load on this factor. EC accounted for $18.03 \%$ of the variance.

Like Korean compound task, English compound task also included variance in the mode of response (comprehension vs. production), in the type of stimulus (real vs. pseudo words), and in the structure of the compound (noun-noun vs. noun-verb). The factor analysis suggests that the mode of response rather than the other two variances - type of stimulus and structure of compounds - can be seen as dimensions emerging from the factor analysis. This factor analysis provides evidence for the construct validity of these tasks. The high reliability of all the items within a single task suggests that they can be used as a single measure in the regression analyses later on.

In sum, the participants represent typically developing children in terms of general verbal ability. The split-half coefficient for the vocabulary test and Cronbach's alpha coefficient for the compound task showed a good reliability of the measures. The results of factor analyses satisfied the criteria of construct validity in the compound task measures including both the discriminant validity (loading of at least .4 and no cross-loading of items above .4) and convergent validity (evgenvalues of 1 and loading of at least .4, items that load on posited constructs). 


\subsection{Correlation Analysis}

The Pearson product moment correlation coefficient $(r)$ was conducted to examine the relationship between all the variables and the results are presented in Table 7. The majority of the correlations is significant, except for those that examine the relation between gender and the test scores. Thus, it was not expected that controlling for gender in partial correlations would significantly affect the results, but it clearly was important to control for grade and verbal ability.

Table 7. Correlation between the variables

\begin{tabular}{|c|c|c|c|c|c|}
\hline & Korean & English & Gender & Grade & Verbal Ability \\
\hline Korean & - & & & & \\
\hline English & $.532 * *$ & - & & & \\
\hline Gender & .191 & .101 & - & & \\
\hline Grade & $.196^{*}$ & $.290 * *$ & -.018 & - & \\
\hline VA & $.281^{* *}$ & $.380^{* *}$ & -.132 & .002 & - \\
\hline
\end{tabular}

\subsubsection{Korean and English Compound Test Scores}

The first research question was to examine whether there is a relationship between performance in the Korean and English compound tasks. To measure participants' ability to comprehend and produce compound words, all the Korean children were given a Korean and English compound task. As can be seen in Table 7, the correlation between Korean and English test scores was positive and statistically significant $(r=.532, p<.01)$. A specific relation between Korean children's understandings of the structure of compounds in Korean and English will be explained by the results of regression analysis.

\subsubsection{Gender and Compound Test Scores}

The second research question was to examine whether gender affects the performance of the Korean and English compound tasks. Table 8 presents the summary statistics of the tasks by gender group. The mean scores of the Korean task were higher than those of the English task regardless of gender. In addition, girls scored higher in both Korean and English tasks than boys, which was generally consistent with the stereotype that girls outperform boys at school.

Table 8. Descriptive statistics for Korean and English compound task scores by gender

\begin{tabular}{lllll}
\hline \multirow{2}{*}{ Classes } & Boys & \multicolumn{3}{l}{ Girl } \\
\cline { 2 - 5 } & $\mathrm{M}$ & $\mathrm{SD}$ & $\mathrm{M}$ & $\mathrm{SD}$ \\
\hline Korean & 26.23 & 4.232 & 27.83 & 4.097 \\
\hline English & 18.40 & 8.428 & 20.07 & 8.042 \\
\hline
\end{tabular}

When an independent sample $t$ test was conducted to test for gender difference in the Korean and English task performance, there was no significant gender difference in the Korean task $(t(104)=-1.981)$ and the English task $(t(104)=-1.032)$. As shown in Table 7, gender was more correlated with Korean $(r=.191)$ than English $(r$ $=.101$ ), but the two correlations were not significant. As expected from the less significant correlation between gender and the test scores, the correlation between the Korean and English compound task performance $(r=.532$, $p<.01)$ still remained significant $(r=.525, p<.01)$, after controlling for gender. Thus, the connections between Korean and English scores in the compound task could not be explained by the effect of gender.

\subsubsection{Grade and Compound Test Scores}

The third research question was to examine the effects of grade on the Korean and English test scores. Table 9 shows the summary statistics of the Korean and English test scores in each grade. The mean scores of the Korean task were higher than those of the English task in both grades. In addition, the mean scores of sixth graders were higher than those of fifth graders, which is consistent with the general idea that older children perform better 
than younger children.

Table 9. Descriptive statistics for Korean and English compound task scores by grade

\begin{tabular}{lllll}
\hline \multirow{2}{*}{ Classes } & \multicolumn{2}{l}{ Grade 5} & \multicolumn{3}{c}{ Grade 6 } \\
\cline { 2 - 5 } & $\mathrm{M}$ & $\mathrm{SD}$ & $\mathrm{M}$ & $\mathrm{SD}$ \\
\hline Korean & 26.27 & 4.547 & 27.92 & 3.675 \\
\hline English & 17.02 & 7.967 & 21.78 & 7.865 \\
\hline
\end{tabular}

When children's performance on the Korean and English tasks was compared using a one-way ANOVA, there was a significant effect of grade on the Korean task, $F(1,105)=4.169, p<.05$. and on the English task, $F(1$, $105)=9.550, p<.01$. Therefore, grade was significant in the test outcomes. As shown in Table 6, grade was more correlated with English $(r=.290, p<.01)$ than Korean $(r=.196, p<.05)$, but the correlation was significant in both cases. A hypothesis was that if grade had an impact, the association between the Korean and English test scores could be weakened once grade was controlled for. Therefore, a partial correlation analysis was conducted to examine whether there is the effect of grade on the Korean and English compound task performance. When grade was partialled out, the correlation between the Korean and English compound task performance $(r=.532, p<.01)$ still remained significant $(r=.506, p<.01)$, which means that the relation between these two abilities is specific and not attributable to the children's grade.

\subsubsection{Verbal Ability and Compound Test Scores}

The fourth research question was to examine the effects of verbal ability on the Korean and English compound task performance. As shown in Table 6, verbal ability was more correlated with English $(r=.380, p<.01)$ than Korean $(r=.281, p<.01)$, but the correlation was significant in both cases. This is the same case of grade, but not gender. When verbal ability was partialled out, the correlation between Korean and English compound task performance $(r=.532, p<.01)$ was slightly weakened but still remained significant $(r=.479, p<.01)$. This means that the relation between the Korean and English tasks was specific and cannot be attributed to the effect of verbal ability.

The results from the correlation analyses indicate that the correlations between all the variables were significant, except the relation between gender and the test scores. Grade and verbal ability were more correlated with the English task, whereas gender was more correlated with the Korean task. When each of the three independent variables (i.e., gender, grade, verbal ability) was partialled out, the correlation between Korean and English test scores was still significant, indicating that children's ability to deal with compounds in Korean and English was not affected by those variables. Thus, it is useful to examine which is the strong predictor of the English task.

\subsection{Regression Analysis}

Multiple linear regression was employed to help determine which of the four variables (i.e., gender, grade, verbal ability, Korean) has the greatest predictive power of the English task performance. As can be seen in Table 10, all the four variables were entered in a fixed order into the multiple regression so as to ensure that all the controls were accounted for before the relation between the Korean and the English tasks was analyzed. This hierarchical regression was used to see a specific relation between Korean children's understandings of the structure of Korean and English compounds. The results of the regression analysis indicates that children's verbal ability and Korean test scores contributed significantly to the prediction of the English test scores. The combined set of variables produced a multiple correlation of .62, accounting for $36.2 \%$ of the overall variance. Verbal ability $\left(R^{2}\right.$ change $=.23, F$ change $(1,102)=21.485, p<.001)$ and Korean test scores $\left(R^{2}\right.$ change $=.39, F$ change $(1,101)=$ $21.985, p<.001)$ significantly predicted the outcomes of the English task. Therefore, children's Korean task performance was a reliable predictor of the English task performance, which is then followed by verbal ability. 
Table 10. Multiple regression on the English task performance

\begin{tabular}{|c|c|c|c|c|c|c|c|c|c|}
\hline \multirow[b]{2}{*}{ Mode } & \multirow[b]{2}{*}{$R$} & \multirow[b]{2}{*}{$\begin{array}{l}R \\
\text { Square }\end{array}$} & \multicolumn{7}{|c|}{ Change Statistics } \\
\hline & & & $\begin{array}{l}\text { Adjusted } \\
R \text { Square }\end{array}$ & $\begin{array}{l}\text { Std. Error or } \\
\text { the Estimate }\end{array}$ & $\begin{array}{l}R \text { Square } \\
\text { Change }\end{array}$ & $\begin{array}{l}F \\
\text { Change }\end{array}$ & df1 & $\mathrm{df} 2$ & $\begin{array}{l}\text { Sig. } F \\
\text { Change }\end{array}$ \\
\hline 1 & $.101^{\mathrm{a}}$ & .010 & .001 & 8.234 & .010 & 1.065 & 1 & 104 & .304 \\
\hline 2 & $.309^{\mathrm{b}}$ & .095 & .078 & 7.910 & .085 & 9.697 & 1 & 103 & .002 \\
\hline 3 & $.503^{\mathrm{c}}$ & .253 & .231 & 7.224 & .157 & 21.485 & 1 & 102 & .000 \\
\hline 4 & $.621^{\mathrm{d}}$ & .386 & .362 & 6.581 & .133 & 21.985 & 1 & 101 & .000 \\
\hline
\end{tabular}

Note. a. Predictors: (constant), Gender / b. Predictors: (constant), Gender, Grade / c. Predictors: (constant), Gender, Grade, Verbal ability / d. Predictors: (constant), Gender, Grade, Verbal ability, Korea

As the last step in the multiple regression analysis, the relative weights of each individual predictor in predicting the performance of the English task was calculated. According to the beta coefficients of the four variables in Table 11, Korean test scores, with a beta coefficient of 0.40 , contributed more to the prediction of the English compound test scores than verbal ability, with a beta coefficient of 0.28 and grade, with a beta coefficient of 0.21 . This was borne out by the strong correlations between Korean and English in the correlation matrix in Table 7 .

Table 11. Coefficients of the English task performance

\begin{tabular}{llllll}
\hline & \multicolumn{2}{l}{$\begin{array}{l}\text { Unstandardized } \\
\text { Coefficients }\end{array}$} & \multicolumn{2}{l}{$\begin{array}{l}\text { Standardized } \\
\text { Coefficients }\end{array}$} & $\mathrm{p}$ \\
\cline { 2 - 4 } & $\mathrm{B}$ & Std. Error & $\beta$ & & \\
\hline (constant) & -74.498 & 19.496 & & -3.821 & .001 \\
Gender & 1.055 & 1.332 & .064 & .792 & .430 \\
Grade & 3.478 & 1.311 & .212 & 2.653 & .009 \\
Verbal & .542 & .163 & .275 & 3.312 & .001 \\
\hline
\end{tabular}

\section{Discussion}

\subsection{Korean as L1 and English as L2}

To answer the first research question, a Korean and English compound task was designed to include variation in the mode of response (comprehension vs. production), in the type of stimulus (real vs. pseudo words), and in the structure of the compound (noun-noun vs. noun-verb). As reported above, three factors in the Korean task and two factors in the English task emerged from the factor analyses. This indicated that the mode of response and structure of the compound could be seen as dimensions in the measurement of children's understanding of Korean and English compounds. The results of correlation analysis showed a statistically significant correlation between the Korean and English task performance $(r=.532, p<.01)$. An examination of the magnitude of the beta coefficients revealed Korean to have the largest impact in the explanation of variations of the English task performance. Thus, Korean was the most reliable predictor of the outcomes of the English task performance among the four predictors. In other words, Korean children's L1 ability to deal with compounds was the strongest predictor of English L2 compound task performance. This supports evidence that children's L1 morphological awareness is transferable to L2 morphological processes (Odlin, 1989; Koda, 2000, 2008). Despite the linguistic distance between Korean and English, the transfer of morphological knowledge from Korean to English might be attributed from the common word formation process, compounding in the two languages. Thus, given the similarity in the Korean and English morphological formation process, it can be possible to expect that Korean L1 compound awareness will influence English L2 compound process. This is important because English L2 morphological awareness is expected to enhance the development of English literacy skill. The significant correlation between Korean and English and the transfer of morphological knowledge from Korean to English will provide teachers with useful information when designing compound word tasks for classroom activities to develop their students' awareness of morphology. 


\subsection{Gender}

To date, scant research has discussed the role of gender in relation to morphological awareness except a classic study of Berko (1958), who reported no gender difference in the acquisition of morphological rules of English. The mean scores of the Korean and English tasks revealed that girls scored higher than boys, which is consistent with the general idea that girls are superior to boys in terms of language development. However, the result of an independent sample $t$ test confirmed no gender effect on the Korean and English task performance. In addition, gender was less correlated with Korean and English than other two variables (i.e., grade and verbal ability). Therefore, it was concluded that gender was not a reliable predictor of the English L2 compound task performance.

\subsection{Grade}

As shown in a general idea that morphological awareness increases with age (Carlisle, 1995, 2005; Deacon \& Kirby, 2004; Deacon et al., 2007; Nunes, 1997a, 1997b), the sixth grade children outperformed the fifth grade children in both Korean and English. This makes it possible to assume that the younger children can perform better when they grow up. In addition, the results from a one-way ANOVA revealed the significant effects of grade on the Korean and English task. This supports evidence that grade is a significant factor in the task performance. From the regression analysis, however, grade did not have a considerable impact in the explanation of variations of the English task performance among the four predictors. Although the older children performed better than the young children in both tasks, grade was not a powerful predictor of the English task performance compared to Korean task performance and verbal ability. For this reason, the research findings raise practical issues such as when and how Korean children should be taught about morphemes in order to develop their awareness of morphology and literacy skills in English L2 learning.

\subsection{Verbal Ability}

The results of correlation analysis revealed that verbal ability was significantly correlated with Korean and English task performance, even with a strong correlation between verbal ability and English rather than Korean. In other words, children's verbal ability was a sensitive factor when performing the English compound task. As shown in the correlation analysis, the relation between Korean and English compound task performance still remained significant after verbal ability partialled out, indicating that children's task performance did not stem from their verbal ability. However, the results of the regression analysis revealed that verbal ability had a considerable impact in the explanation of variations of the English task performance among the four predictors. Based on these findings, this study concludes that verbal ability was a reliable predictor of the English compound task performance. From the practical perspective, therefore, it is important for teachers who work with children with poor or good verbal ability, because L2 compound awareness seemed to be affected by the children's verbal ability and in turn, their verbal ability will be a significant factor when predicting successful literacy development.

\section{Conclusion}

The current study revealed that Korean task performance had the largest impact on the English task performance. In other words, Korean L1 morphological awareness contributed to English L2 morphological process. For the theoretical contribution, this finding reinforces the conception of morphological awareness as a phenomenon with cross-linguistic significance. For the educational implication, this study supports that Korean children's awareness of compounds in Korean can impact their awareness of compounds in English L2 morphological awareness, which can in turn enhance children's English literacy skills. When three individual differences (i.e., grade, gender, verbal ability) were examined, grade was another significant predictor of the English task performance. This may provide teachers and researchers with practical information to develop Korean students' L1 morphological awareness in relation to English L2 literacy development. For the measurement of Korean children's ability to comprehend and produce compounds, a set of Korean and English compound task was developed, showing an excellent reliability. This means that other researchers can replicate the newly-developed quantitative instrument with practical information to develop a new instrument to test students' morphological awareness in relation to L2 literacy development.

As addressed above, morphology is important to orthographies such as Korean and English and morphological awareness plays a significant part for English-speaking and English-learning children in developing literacy skills. Children with a large repertoire of words can comprehend texts more easily than other children with a lack of word knowledge. The large growth in word knowledge is made possible by the children's morphological awareness of new words. In Korea where English is regarded as a national issue, there are urgent educational needs to conduct longitudinal and intervention studies to examine the contributions of morphological awareness 
to English L2 literacy development and to design a variety of morphological awareness programs to develop children's English L2 morphological awareness. In particular, compounding is the most productive word formation process as well as an effective way of increasing word knowledge in both Korean and English. Therefore, there are practical considerations to develop compound awareness for Korean children's English L2 literacy development.

\section{References}

Bauer, L. (1983). English word-formation. Cambridge: Cambridge University Press.

Berko, J. (1958). The child's learning of English morphology. Word, 14(2/3), 150-177. http://doi.org/10.1111/j.1467-1770.1969.tb00463.x

Bryant, P., \& Nunes, T. (2004). Morphology and spelling. In T. Nunes, \& P. Bryant (Eds.), Handbook of children's literacy (pp. 91-117). Dodrecht, Netherlands: Kluwer.

Carlisle, J. F. (1995). Morphological awareness and early reading achievement. In L. B. Feldman (Ed.), Morphological aspects of language processing (pp. 189-209). Hillsdale, NJ: Erlbaum.

Carlisle, J. F. (2005). Morphological process that influence learning to read. In C. A. Stone, E. R. Silliman, B. J. Ehren, \& K. Apel (Eds.), Handbook of language and literacy: Development and disorders (pp. 318-339). New York: Guilford Press.

Carlisle, J. F., \& Nomanbhoy, D. (1993). Phonological and morphological awareness in first graders. Applied Psycholinguistics, 14(2), 177-195. http://doi.org/10.1017/S0142716400009541

Carlo, M. S., August, D., Mclaughlin, B., Snow, C. E., Dressler, C., Lippman, D. N., ... White, C. E. (2004). Closing the gap: Addressing the vocabulary needs of English-language learners in Bilingual and mainstream classrooms. Reading Research Quarterly, 39(2), 188-215. http://doi.org/10.1598/RRQ.39.2.3

Carstairs-McCarthy, A. (2002). An introduction to English morphology: Words and their structure. Edinburgh: Edinburgh University Press.

Cho, J. R., McBride-Chang, C., \& Park, S. G. (2008). Phonological awareness and morphological awareness: Differential associations to regular and irregular word recognition in early Korean Hangul readers. Reading and Writing, 21(3), 255-274. http://doi.org/10.1007/s11145-007-9072-z

Cohen, L., Manion, L., \& Morrison, K. (2000). Research methods in education (5th ed.). London: Routledge.

Crystal, D. (2006). Language and the Internet (2nd ed.). Cambridge: Cambridge University Press.

Deacon, H., \& Kirby, J. (2004). Morphological awareness: Just "more phonological?" The roles of morphological and phonological awareness in reading development. Applied Psycholinguistics, 25(2), 223-238. http://doi.org/10.1017/S0142716404001110

Fabb, N. (2001). Compounding. In A. Spencer, \& A. M. Zwicky (Eds.), The Handbook of morphology (pp. 66-83). Oxford: Blackwell.

Feldman, L. B. (1995). Morphological aspects of language processing. Hillsdale, NJ: Erlbaum.

Fowler, A. E., \& Liberman, I. Y. (1995). The role of phonology and orthography in morphological awareness. In L. B. Feldman (Ed.), Morphological aspects of language processing (pp. 157-188). Hillsdale, NJ: Erlbaum.

Gillion, G. (2004). Phonological awareness: From research to practice. New York: Guilford Press.

Healey, J. F. (2005). Statistics: A tool for social research (7th ed.). Belmont, CA: Cengage Learning.

Jong, Y. O. (2009). An investigation into the benefits of collaborative writing for the development of EFL children's communication skills: A reflective report of a teacher researcher (Unpublished doctoral dissertation). University of Warwick, Coventry, UK.

Jong, Y. O. (2013). Effective approaches to teaching English writing: A hybrid English writing model. Saarbrucken: LAP.

Koda, K. (1996). L2 word recognition research: A critical review. The Modern Language Journal, 80(4), 450-460. http://doi.org/10.1111/j.1540-4781.1996.tb05465.x

Koda, K. (2000). Cross-linguistic variations in L2 morphological awareness. Applied Psycholinguistics, 21(3), 297-320. http://doi.org/10.1017/S0142716400003015

Koda, K. (2005). Insights into second language reading: Across-linguistic approach. Cambridge: Cambridge University Press. 
Koda, K. (2008). Impacts of prior literacy experience on second language learning to read. In K. Koda, \& A. Zehler (Eds.), Learning to read across languages: Cross-linguistic relationships in first- and second-language literacy development (pp. 68-96). London: Routledge.

Koda, K., \& Zehler, A. (2008). Learning to read across languages: Cross-linguistic relationships in first- and second-language literacy development. London: Routledge.

Ku, Y. M., \& Anderson, R. (2003). Development of morphological awareness in Chinese and English. Reading and Writing: An Interdisciplinary Journal, 16(5), 399-422. http://doi.org/10.1023/A:1024227231216

Kuo, L., \& Anderson, R. (2006). Morphological awareness and learning to read: A cross-language perspective. Educational Psychologist, 41(3), 161-180. http://doi.org/10.1207/s15326985ep4103_3

Lee, G. L. (2002). The role of Korean parents in the literacy development of their children. International Journal of Early Childhood, 34(1), 1-8. http://doi.org/10.1007/BF03177318

Lee, I. S., \& Ramsey, S. R. (2000). The Korean language. Albany, NY: SUNY Press.

Lee, J. H., Park, E. H., \& Kim, H. J. (2000). Literacy education in Korea: A sociocultural perspective. Childhood Education, 76(6), 347-351. http://.doi.org/10.1080/00094056.2000.10521180

Lee, P. H. (2003). A history of Korean literature. Cambridge: Cambridge University Press.

McBride-Chang, C., Cho, J.-R., Liu, H., Wagner, R., Shu, H., Zhou, A., ... Muse, A. (2005). Changing models across cultures: Associations of phonological and morphological awareness to reading in Beijing, Hong Kong, Korea, and America. Journal of Experimental Child Psychology, 92(2), 140-160. http://doi.org/10.1016/j.jecp.2005.03.009

Ministry of Education, Korea. (2007). Oegugeogwa Gyoyukgwajeong [Foreign language curriculum I]. Seoul, Korea: Ministry of Education.

Morrow, V., \& Richards, M. (1996). The ethics of social research with children: An overview. Children \& Society, 10(2), 90-105. http://doi.org/10.1111/j.1099-0860.1996.tb00461.x

Murphy, V., \& Nicoladis, E. (2006). When answer-phone makes a difference in children's acquisition of English compounds. Child Language, 33(3), 677-691. http://doi.org/10.1017/S030500090600746X

Nagy, W., Berninger, V. W., \& Abbott, R. C. (2006). Contribution of morphology beyond phonology to literacy outcomes of upper elementary and middle-school students. Journal of Educational Psychology, 98(1), 134-147. http://doi.org/10.1037/0022-0663.98.1.134

Nagy, W., Berninger, V., Abbott, R., Vaughan, K., \& Vermeulen, K. (2003). Relationship of morphology and other language skills to literacy skills in at-risk second-grade readers and at-risk fourth-grade writers. Journal of Educational Psychology, 95(4), 730-742. http://doi.org/10.1037/0022-0663.95.4.730

Nation, I. S. P. (2001). Learning vocabulary in another language. Cambridge: Cambridge University Press.

Nicoladis, E. (2003a). What compound nouns mean to preschool children. Brain and Language, 84(1), 38-49. http://doi.org/10.1016/S0093-934X(02)00519-9

Nicoladis, E. (2003b). Cross-linguistic transfer in deverbal compounds of preschool bilingual children. Bilingualism: Language and Cognition, 6(1), 17-31. http://doi.org/10.1017/S1366728903001019

Nunes, T., \& Bryant, P. (2009). Children's reading and spelling: Beyond the first steps. West Sussex: Wiley-Blackwell.

Odlin, T. (1989). Language transfer: Cross-linguistic influence in language learning. Cambridge: Cambridge University Press.

Park, E. Y. (2008). Literacy experience in Korean: Implications for learning to read in a second language. In K. Koda, \& A. Zehler (Eds.), Learning to read across languages: Cross-linguistic relationships in first- and second-language literacy development (pp. 201-221). New York: Routledge.

Park, J. K. (2009). 'English fever' in South Korea: Its historical and symptoms. English Today, 25(1), 50-57. http://doi.org/10.1017/S026607840900008X

Plag, I. (2003). Word-formation in English. Cambridge: Cambridge University Press.

Ramirez, G., Chen, X., Geva, E., \& Kiefer, H. (2010). Morphological awareness in Spanish-speaking English language learners: Within and cross-language effects on word reading. Reading and Writing, 23(3/4), 337-358. http://doi.org/10.1007/s11145-009-9203-9 
Seoul Community Rehabilitation Center. (2009). Receptive and expressive vocabulary test (REVT). Seoul, Korea: Seoul Community Rehabilitation Center.

Shin, H. J. (2007). English language teaching in Korea: Toward globalization or glocalization? In J. Cummins, \& C. Davison (Eds.), International handbook of English language teaching (Part 1) (pp. 75-86). New York: Springer.

Song, J. J. (2005). The Korean language: Structure, use and context. New York: Routhledge.

Wang, M., Cheng, C., \& Chen, S.-W. (2006a). Contribution of morphological awareness to Chinese-English biliteracy acquisition. Journal of Educational Psychology, 98(3), 542-553. http://doi.org/10.1037/0022-0663.98.3.542

Wang, M., Ko, I. Y., \& Choi, J. H. (2009). The importance of morphological awareness in Korean-English biliteracy acquisition. Contemporary Educational Psychology, 34(2), 132-142. http://doi.org/10.1016/j.cedpsych.2008.12.002

Wang, M., Park, Y. J., \& Lee, K. R. (2006b). Korean-English biliteracy acquisition: Cross-language phonological and orthographic transfer. Journal of Educational Psychology, 98(1), 148-158. http://doi.org/10.1037/0022-0663.98.1.148

Wang, M., Perfetti, C., \& Liu, Y. (2005). Chinese-English biliteracy acquisition: Cross-language and writing system transfer. Cognition, 97(1), 67-88. http://doi.org/10.1016/j.cognition.2004.10.001

\section{Copyrights}

Copyright for this article is retained by the author(s), with first publication rights granted to the journal.

This is an open-access article distributed under the terms and conditions of the Creative Commons Attribution license (http://creativecommons.org/licenses/by/3.0/). 